\title{
Improved Sea Surface Height from Satellite Altimetry in Coastal Zones: A Case Study in Southern Patagonia
}

Lago LS ${ }^{1}$, Saraceno $\mathrm{M}^{1,2,3}$, Ruiz Etcheverry $\mathrm{LA}^{4}$, Passaro $\mathrm{M}^{5}$, Oreiro $\mathrm{F}^{6,7}$, D’Onofrio ${ }^{6,7} \mathrm{EE}$, González $\mathrm{R}^{8}$

1 Departamento de Cs de la Atmósfera y los Océanos FCEN UBA, CABA, Argentina. 2 Centro de Investigación del Mar y la Atmósfera, CABA, Argentina. 3 UMI-FAECI, CABA, Argentina. 4 International Pacific Research Center, School of Ocean and Earth Science and Technologil Hawaii, USA. 5 Deutsches Geodätisches Forschungsinstitut der Technischen Universität München, München, Germany. 6 Departamento de Oceanografía SHN, CABA, Argentina. 7 Facultad de Ingenierria UBA, CABA, Argentina. 8 CONICET - Escuela Superior de Cienciaa

\section{OBJECTIVES}

- To validate satellite altimetry data in a highly dynamic coastal region dominated by a large tidal regime: San Matias Gulf (SMG) in Southern Patagonia, Argentina.

- To describe how close to the coast the altimetric data is reliable by analyzing the performance of :

- the retracking method

- the satellite corrections, especially the ocean tide correction.

\section{MOTIVATION}

Satellite altimetry measurements have become an essential and accessible dataset to understand ocean dynamics, monitor climate change and improve forecasts and realtime products through assimilation in ocean operational models, among others.

\section{DATA}

\section{In Situ Data:}

- Bottom Pressure Recorder (BPR):

- Deployed at $1.3 \mathrm{~km}$ from the intersection of tracks 189 and 52 of satellite mission Jason 2 (J2) (Fig.1).

22 months of Sea Surface Height (SSH) time series estimated using BPR measurements (Fig. 2a).

Sampling interval: 2 minutes (April 1 15t 2013 - December 23 2015 ).

- Residual time series was estimated subtracting the tidal signal, predicted with harmonic analysis, from the SSH.

Satellite Data:

-20Hz S-GDR Jason-2 along track Sea Level Anomaly (SLA):

- Satellite tracks considered: ascending and descending tracks \#189 and \#52, respectively. Their crossing point is located $0.9 \mathrm{~km}$ from the coast.

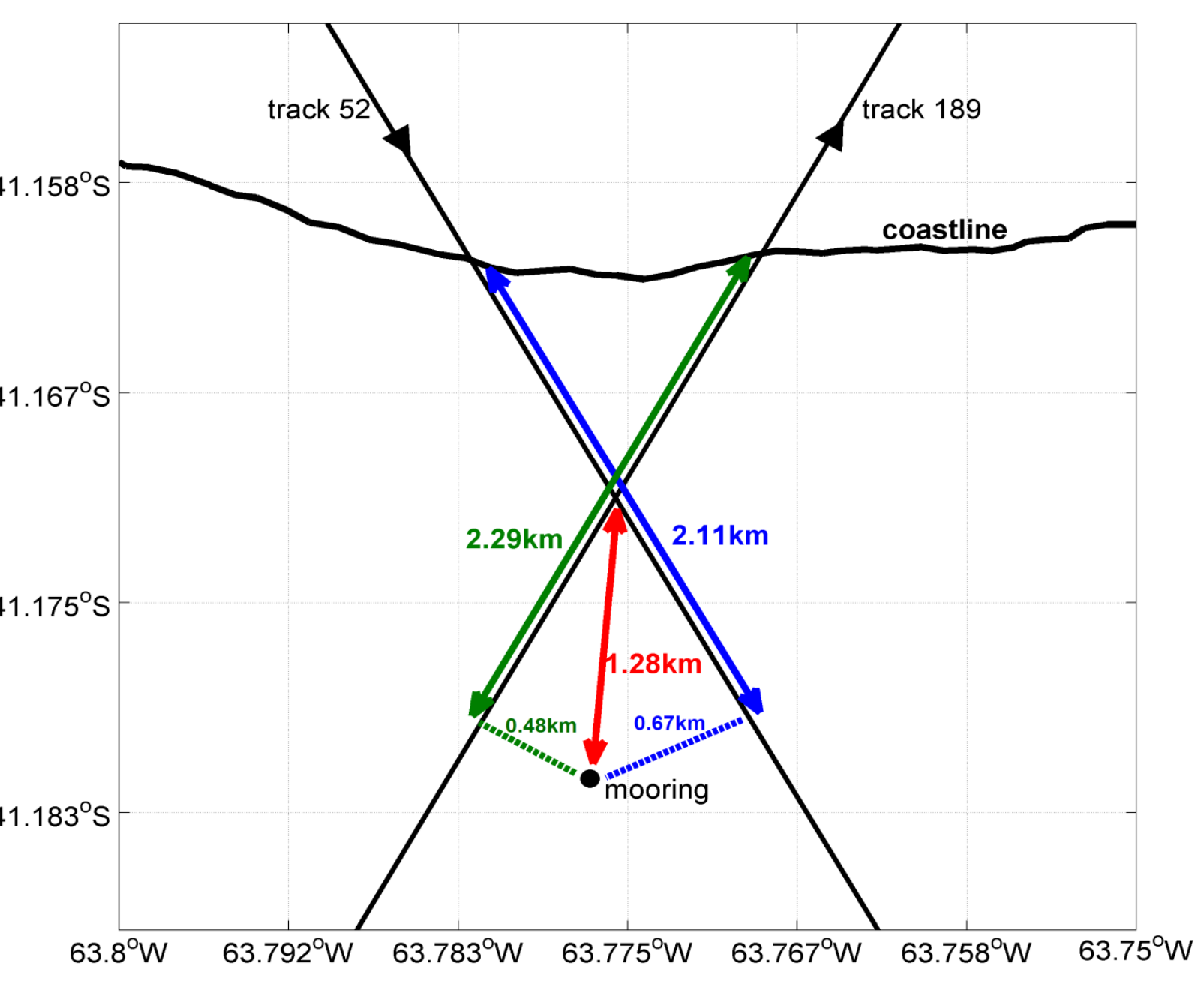

Fig. 2. Jason 2 satellite tracks considered (black line), BPR location (black dot) and relevant distances.
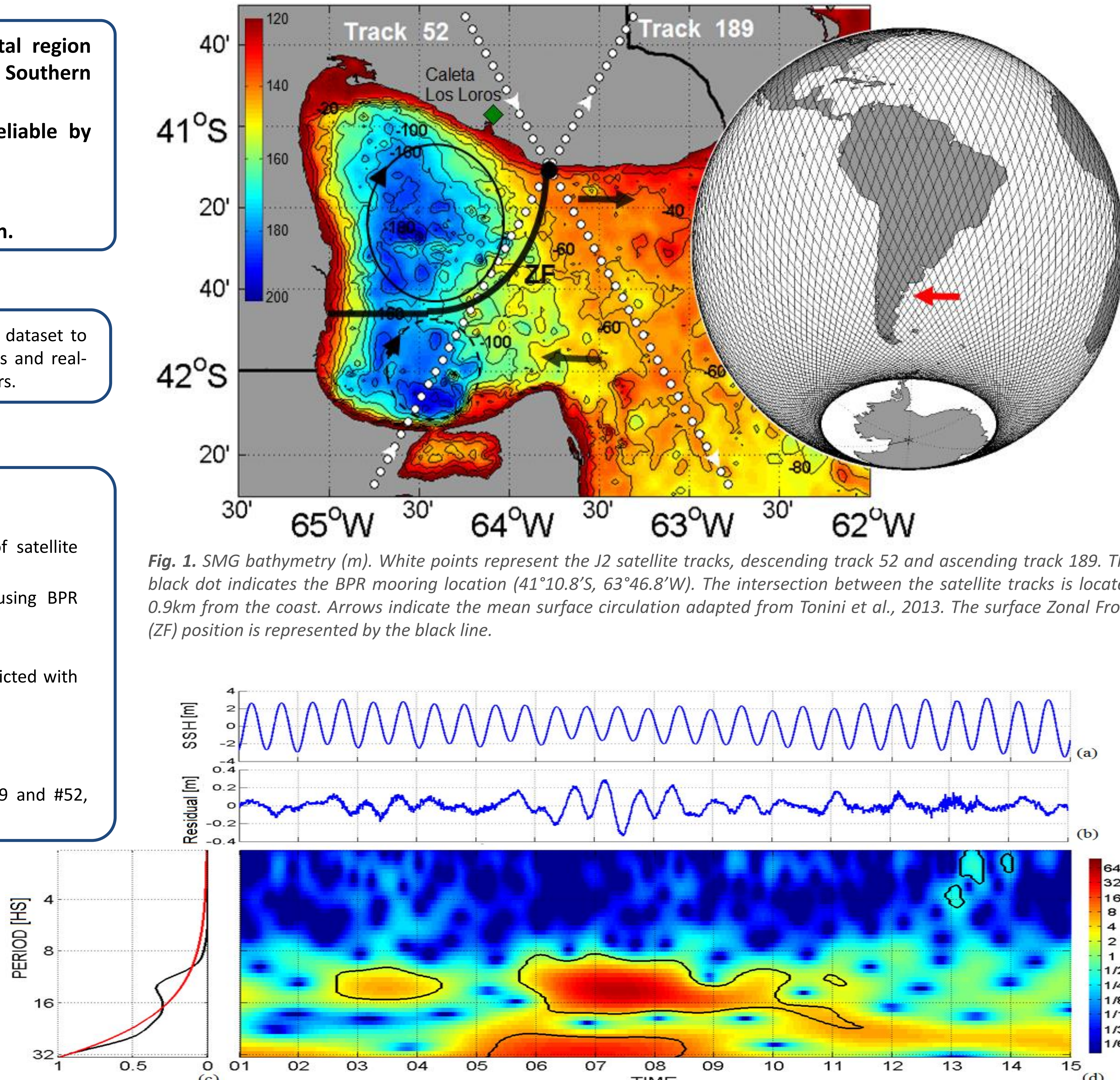

Fig. 1. SMG bathymetry $(\mathrm{m})$. White points represent the J2 satellite tracks, descending track 52 and ascending track 189. The ack dot indicates the BPR mooring location $\left(41^{\circ} 10.8^{\prime} \mathrm{S}, 63^{\circ} 46.8^{\prime} \mathrm{W}\right)$. The intersection between the satellite tracks is located (ZF) position is roast. Arrows indicate the

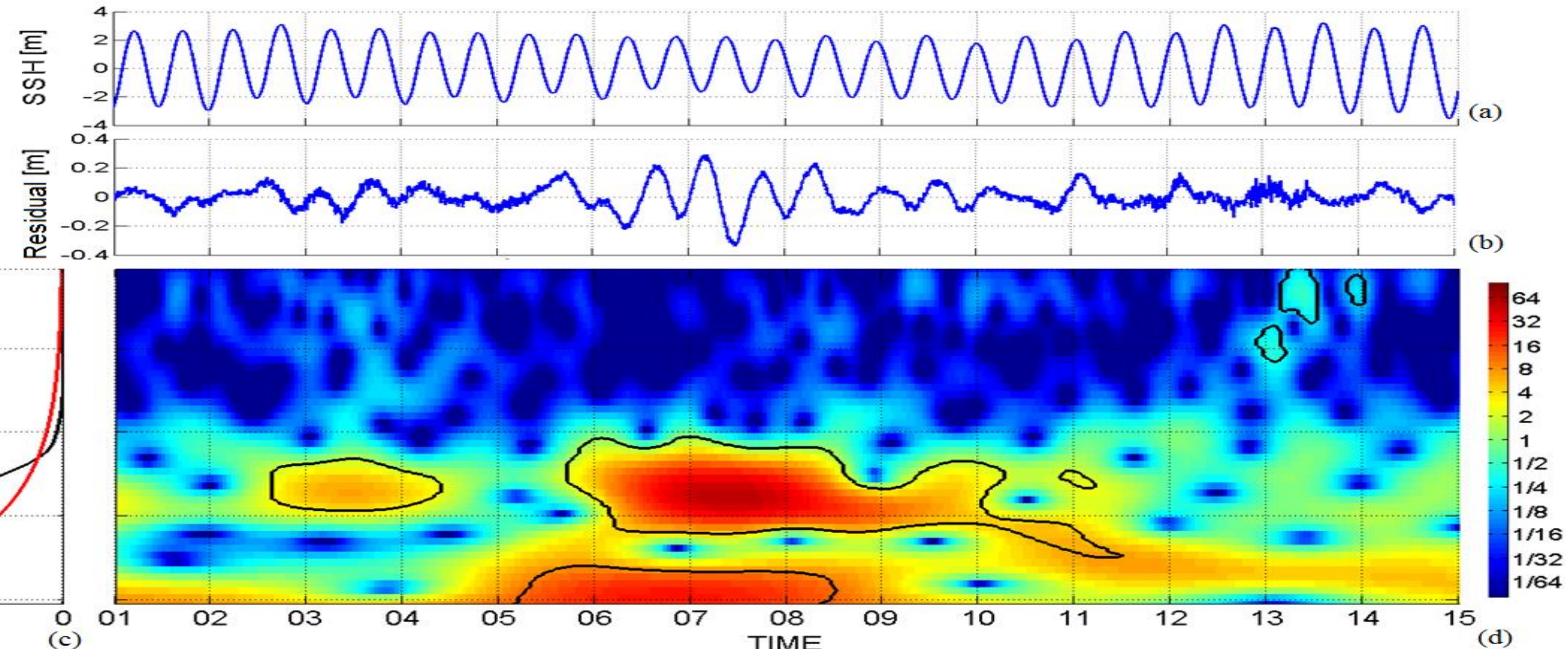

Fig. 3. 15-day segment from $1^{\text {st }}$ to $15^{\text {th }}$ of June 2014 of (a) in situ SSH (m) time series calculated with BPR data; (b) In situ residual (m) time series; and (d) wavelet analysis of the residual,. (c) Global power spectrum (black) of the residual complete time series, and confidence interval (red). The residual time series presents a semidiurnal signal of $24 \mathrm{~cm}$ RMS. The wavelet analysis confirms this is a non-permanent signal with a significant peak centered at $12 \mathrm{hs}$ in the time average spectra of the complete time series. We attribute this signal to non-linear effects.

\section{RESULTS}

Satellite altimetry provides Ocean Tide the best tool to compute

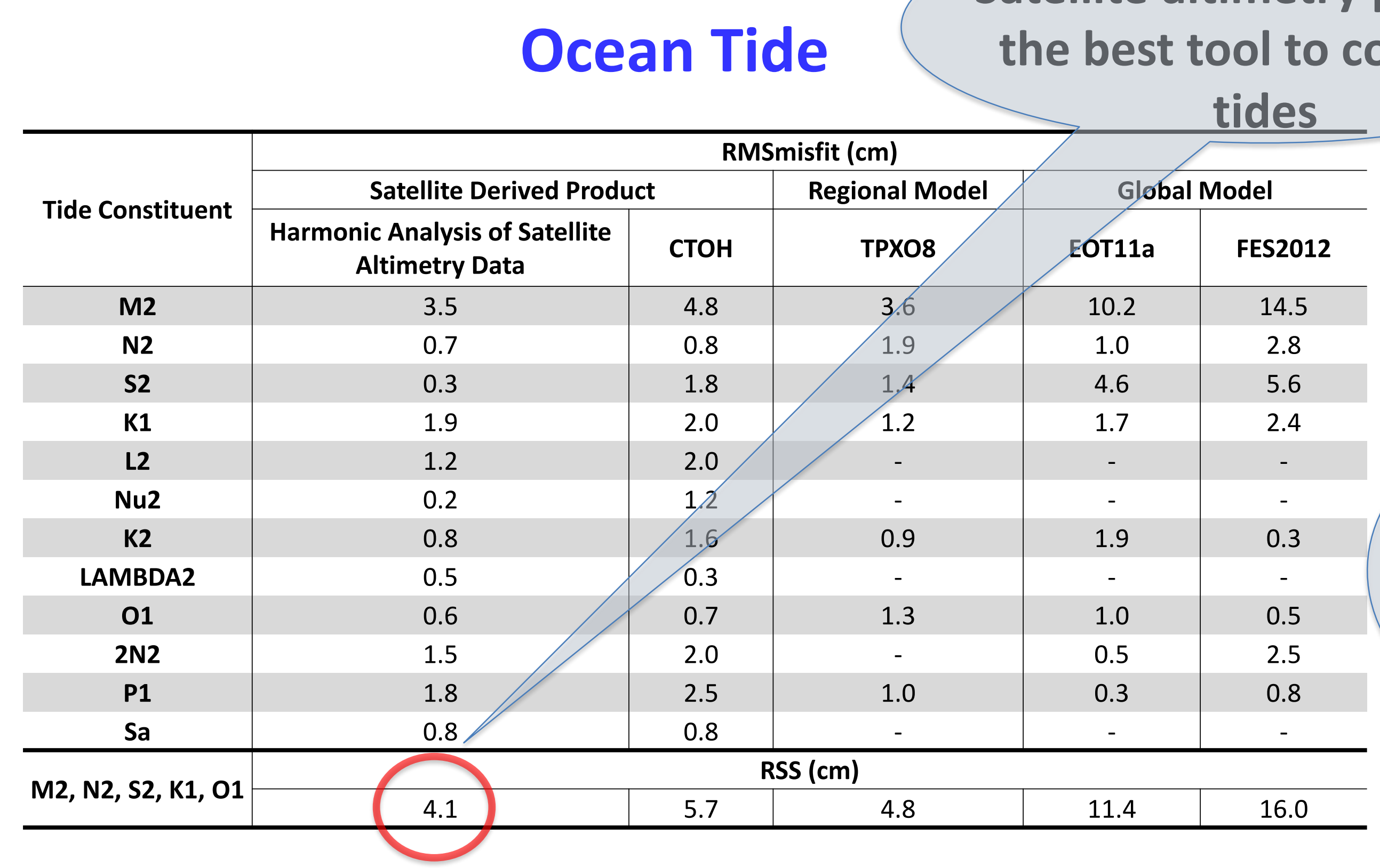

Table 1. Root Mean Square misfit (RMS roduct, for the 12 selected tide constituents. Root Sum Square (RSS) is calculated considering only the 5 constituents present in all data product considered.

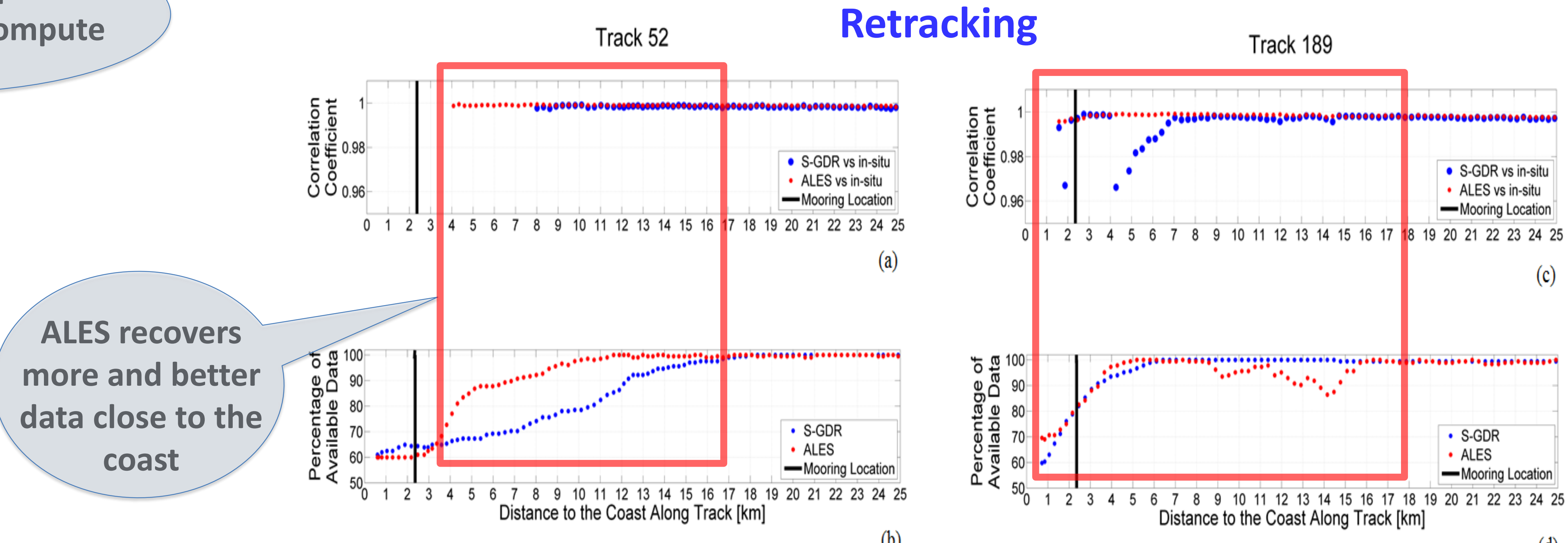

Fig. 4. Correlation coefficient between satellite and in situ SSH (a) and percentage of available SSH satellite data (b) considering the MLE4 range, referred to as S-GDR, (blue) and the ALES range (red); each column represents a different satellite track. The black line corresponds to the location of the BPR mooring. Correlation coefficient was not computed at track points having less than $70 \%$ of available data. ALES bla bla

\section{CONCLUDING REMARKS}

$\checkmark$ San Matias Gulf presents a macrotidal regime: the ocean tidal correction has a large impact in the estimation of satellite sea level anomaly. $\checkmark$ The error in the estimation of tides can be attributed to:

An intermittent semi-diurnal signal that cannot be represented by linear combination of tidal constituents, and remains unpredictable.

The absence of certain constituents in tidal models that present large amplitudes in SMG.

Regional model TPXO8 developed for the Patagonia region best represents tides among models considered. Still, the best representation was obtained by harmonic analyses of a 23 years $1-\mathrm{Hz}$ SLA satellite data. This result remarks the potential of altimetry data to compute tides.

$\checkmark$ Results show that ALES is able to recover more and better data near the coast than the Brown model, in particular for the track with a land-to-ocean transition. For that track, correlation between in situ and altimetry data remains larger than $0.99(95 \% \mathrm{CL})$ up to $1.6 \mathrm{~km}$ from the coast. Using MLE4, data availability stops $8.5 \mathrm{~km}$ from the coast.

We evidenced that the availability of long-term in situ time series of good quality is essential to achieve improvements in coastal altimetry. Further studies are required to comprehend the generation mechanism of th

This study shows satellite altimetry data can be greatly improved in coastal regions, even if they are influenced by macrotidal regimes, by applying advanced retracking methods and accurate tidal models. 